\title{
A Presentation of Persistent Pulmonary Hypertension of a Newborn Mimicking Coarctation of Aorta
}

ISSN: 2576-9200

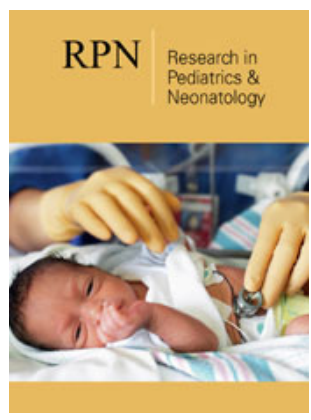

*Corresponding author: Chang-Hsien Yu, Department of Pediatrics, Taitung Mackay Memorial Hospital, Taiwan

Submission: 海 October 27, 2020

Published: 址 November 24, 2020

Volume 5 - Issue 1

How to cite this article: Chang-Hsien Yu. A Presentation of Persistent Pulmonary Hypertension of a Newborn Mimicking Coarctation of Aorta. Research in Pediatrics \& Neonatology. 5(1). RPN. 000605. 2020.

DOI: 10.31031/RPN.2020.05.000605

Copyright $@ \quad$ Chang-Hsien Yu. This article is distributed under the terms of the Creative Commons Attribution 4.0 International License, which permits unrestricted use and redistribution provided that the original author and source are credited.

\section{Chang-Hsien Yu*}

Department of Pediatrics, Taitung Mackay Memorial Hospital, Taiwan

\section{Abstract}

Abbreviation Persistent Pulmonary Hypertension of Newborn (PPHN);Coarctation of Aorta (CoA);Patent Ductus of Arteriosus (PDA).

\section{Introduction}

A male newborn was born to a 18y/o mother at gestational age of 38weeks, birth weight 3295gm via emergent Cesarean section with the indication of fetal distress. The mother was diagnosed with type II DM and pregnancy-induced hypertension. Aspirin was given by a family doctor for prevention of preeclampsia during gestational age of 29 to 36 weeks. After birth, the baby presented persistent desaturation (Sp02 77-85\%) and severe respiratory acidosis despite of resuscitation. CXR revealed cardiomegaly. Echocardiography showed remarkable dilatation of right ventricle and a huge Patent Ductus of Arteriosus (PDA) with almost right-toleft shunt. Persistent Pulmonary Hypertension of Newborn (PPHN) was diagnosed. However, the isthmus of aorta was restricted (the narrowest diameter was $0.220 \mathrm{~cm}$ ) (Figure 1).

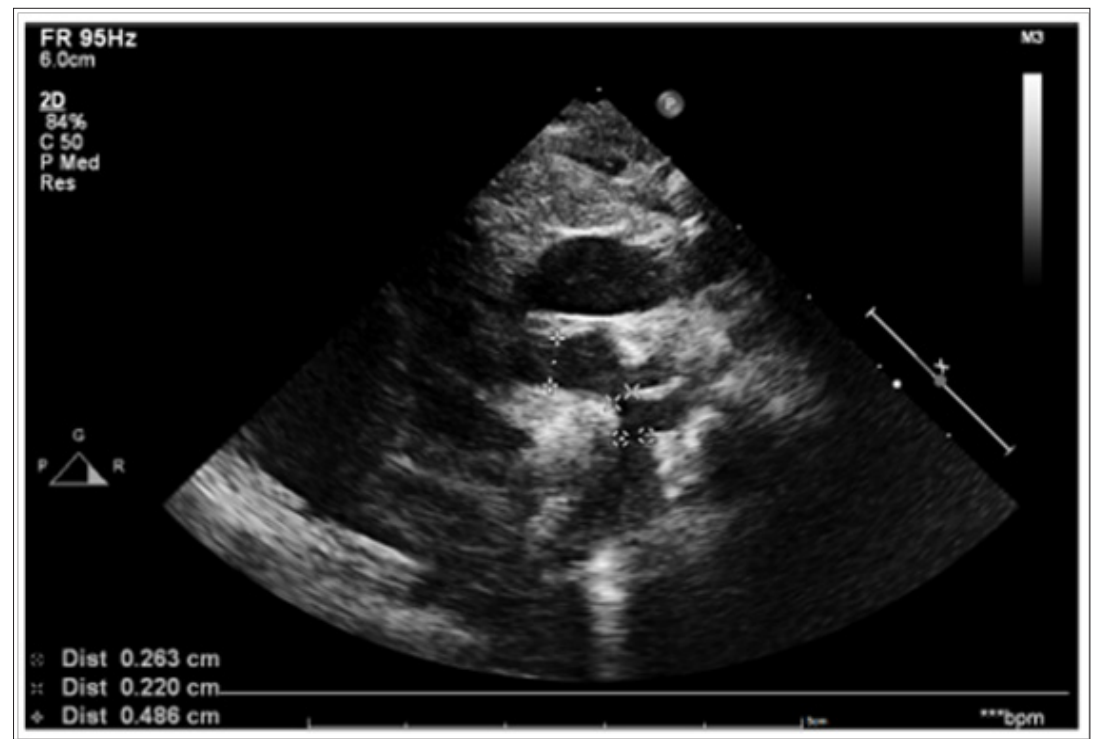

\section{Figure 1:}

Coarctation of aorta was impressed as well. Milrinone and prostaglandin E1 were dripped for right-ventricle dysfunction and to keep the PDA from closure. We hold the use of inhaled nitric oxide because of the suspected CoA. On day 2, his vital signs became more stable and the following echocardiogram showed the diameter of the isthmus of aorta was $0.318 \mathrm{~cm}$. According the clinic manifestation, we asserted it might be not a true coarctation of aorta. Targeting the treatment of pulmonary hypertension, we found that the coarctation of aorta disappeared gradually. On day 4, the shunt of his PDA became almost left-to-right and the diameter of the isthmus of aorta was $0.507 \mathrm{~cm}$ (Figure 2). We discontinued milrinone and prostaglandin E1. Mechanical ventilation was removed smoothly. 


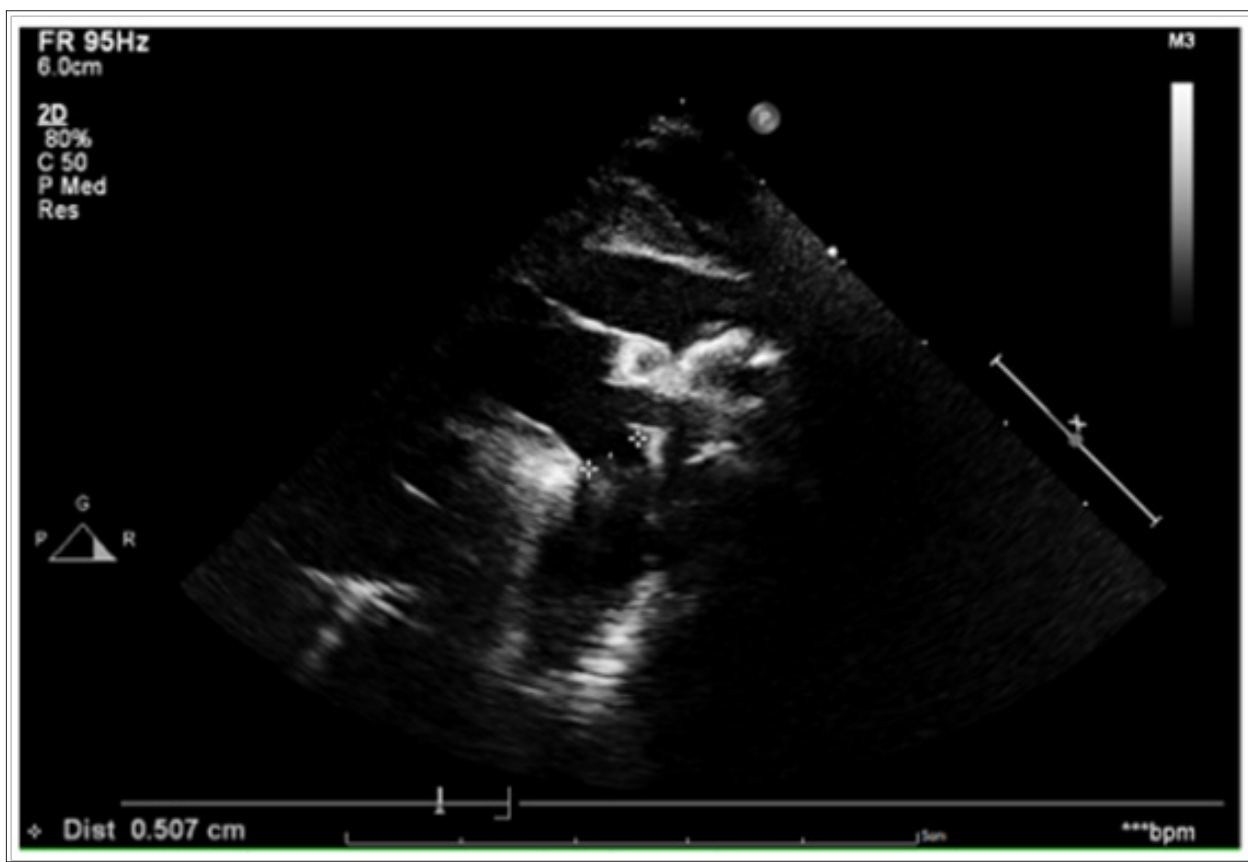

Figure 2:

\section{Discussion}

Though PPHN and severe CoA share the same picture of a large PDA with right-to-left shunt, these two diseases have difference clinical manifestation and onset of symptoms and could be differentiated easily. However, in our case, there was a combined presentation, which would increase the difficulty of management. The "CoA" in our patient was proved to be transient. It was not clear what the association between PPHN and CoA was. For women at high-risk of developing preeclampsia, low-dose aspirin is used to reduce the incidence of preeclampsia [1].

The use of aspirin is safest in the second trimester before 20 weeks. After 30 weeks, there were concerns about prenatal constriction of the ductus arteriosus and PPHN [2]. A possible hypothesis of our case was that aspirin constricted the ductus arteriosus as well as the isthmus of aorta in fetus. After birth, PPHN resulted in the decreased cardiac output of left ventricle, which might augment the appearance of the transient CoA. This theory is evidenced that the transient CoA was improved after resolution of PPHN. In such condition, observation and support care could be used to exclude the real CoA.

\section{References}

1. Duley L, Meher S, Hunter KE, Seidler AL, Askie LM (2019) Antiplatelet agents for preventing pre-eclampsia and its complications. Cochrane Database Syst Rev 2019(10): CD004659.

2. Vermillion ST, Scardo JA, Lashus AG, Wiles HB (1997) The effect of indomethacin tocolysis on fetal ductus arteriosus constriction with advancing gestational age. Am J Obstet Gynecol 177(2): 256-259.

For possible submissions Click below: 